\title{
HIGH PERFORMANCE LIQUID CHROMATOGRAPHY METHOD DEVELOPMENT AND VALIDATION FOR DETECTION AND QUANTIFICATION OF SUBSTANCES RELATED TO ALPHA KETO VALINE CALCIUM SALT
}

\author{
Rajesh A. Jadav ${ }^{\bowtie}$, Mrunal Ambasana and A. H. Bapodra \\ Department of Chemistry and Forensic Science, Bhakta Kavi Narsinh Mehta University, \\ Khadia, Junagadh-362263, Gujarat, India. \\ Corresponding Author: jadavrajesh055@gmail.com
}

\begin{abstract}
A High-Performance Liquid Chromatography method was developed for identification, quantification and control of possible impurities related to $\alpha$-ketovaline calcium salt. A stainless-steel column (YMC Triart-C18: $250 \times 4.6 \mathrm{~mm}$, $5 \mu \mathrm{m}$, made: Japan) and two different mobile phases [Mobile phase A containing $0.1 \%$ of orthophosphoric acid aqueous solution and B containing acetonitrile and methanol in a ratio 90:10 (v/v)] as an eluent at flow rate $1.0 \mathrm{~mL} / \mathrm{min}$ were used to achieve the separation and determination of impurities related to $\alpha$-ketovaline calcium salt. The column temperature was kept $35{ }^{\circ} \mathrm{C}$. The injection volume was $20 \mu \mathrm{l}$. UV detection was performed at $210 \mathrm{~nm}$. The method was validated for Specificity, Limit of Detection (LOD), Limit of Quantification (LOQ), Linearity, Range and Recovery (Accuracy).

Keywords: Keto Analogs, Anticonvulsant, Impurities, HPLC, Renal Failure, Validation
\end{abstract}

RASĀYAN J. Chem., Vol. 14, No.2, 2021

\section{INTRODUCTION}

Ketoacid is one type of organic acid that has a vital role in vivo, and it plays a central role in amino acid metabolism and the process of keeping redox state. $\alpha$-keto valine calcium salt [chemical name: $( \pm)-3-$ Methyl-2-oxobutanoate calcium salt] is one of the main raw material of compound $\alpha$-ketoacid formulation preparation, which is useful to slow down the chronic renal failure (chronic uremia) deterioration and help to cure the uremia symptom; can provide a shield to protein malnutrition..$^{1-5}$ Therefore, these types of salts must be used with fewer impurities as much as possible. Therefore $\alpha$-keto valine calcium salt has importance as a substance for pharmaceutical applications and has been monographed in Pharmacopoeias accordingly (e.g., European Pharmacopoeia). For the sake of convenience $\alpha$-ketovaline calcium salt was abbreviated as " $\alpha-k v c$ " in this text later. Hydantoin is used as starting material in the manufacturing process of $\alpha$-kvc. 5-(Propan-2-Ylidene) imidazolidine-2, 4-dione is the intermediate stage of the process. While DL-2-Hydroxy-3-Methylbutyric acid is the possible impurity of $\alpha$-kvc. The chemical structures of compounds analyzed here are given in Fig.-1.

The maternal use of phenytoin drugs during pregnancy can cause fetal hydantoin syndrome. ${ }^{6}$ Phenytoin is a hydantoin derivative. Phenytoin is extensively metabolized and arene oxide intermediate is generated from the metabolism of phenytoin. ${ }^{7}$ It is thought that this reactive intermediate is responsible for many adverse effects of phenytoin such as damaging the liver and other unpredictable adverse effects which cannot be explained by pharmacologic properties (Idiosyncratic reactions). ${ }^{7}$ So, the presence of hydantoin or its derivatives is harmful to health. 5-(Propan-2-Ylidene) imidazolidine-2, 4-dione is also a hydantoin derivative. So, the amount of hydantoin must be in control.

DL 2-Hydroxy-3-methylbutyric acid is found in urine patients with acidosis (a condition in which a high level of acid is observed in body fluids) and diabetic ketoacidosis (a serious complication of diabetes). The concentration of this metabolite was also abnormally high in the urine of the severely asphyxiated group. In the case of the maple syrup urine disease, when also the amount of the DL 2-Hydroxy-3-methylbutyric was increased in the urine, at that time the early proper diagnosis and treatment can save the brain to damage of the patient and improve prognosis. ${ }^{8,9}$ This method can quantify the compound.

Rasayan J. Chem., 14(2), 950-958(2021)

http://dx.doi.org/10.31788/ RJC.2021.1426272

This work is licensed under a CC BY 4.0 license. 
<smiles>O=C1CNC(=O)N1</smiles>

Hydantoin<smiles>CC(C)C(O)C(=O)O</smiles>

DL-2-hydroxy-3-methyl butanoic acid<smiles>CC(C)=C1NC(=O)NC1=O</smiles>

5-(propan-2-ylidene)imidazolidine-2,4-dione<smiles>CCCCCC(=O)C(C)C</smiles>

Alpha Keto valine Calcium Salt

Fig.-1

Considering Hydantoin, 5-(Propan-2-Ylidene) imidazolidine-2, 4-dione and DL-2-Hydroxy-3Methylbutyric acid (later abbreviated as Imp-1, Imp-2, and Imp-3 respectively in the text) are the possible impurities and the limit of these impurities are not more than $0.50 \mathrm{mg}$ per $100 \mathrm{mg}$ of $\alpha$-kvc individually. The literature reviews related calcium salts keto analogs essential amino acids, disinterment that few analytical methods have been developed for quantification of this type of salts from different biological fluids such as blood, plasma, and serum ${ }^{10-12}$ and also a method of simultaneous quantification of keto analogous acid by UHPLC (latest and fastest technology in liquid chromatography). ${ }^{13}$ But there is no method reported for the quantification of possible impurities present in $\alpha$-kvc. This method outlines the separation of different process-related impurities and the developed method has been validated as per ICH guideline. ${ }^{14}$

\section{Chemicals and Solvents}

\section{EXPERIMENTAL}

The working standard of $\alpha$-kvc, Imp-1, Imp-2, Imp-3 and other samples, HPLC Grade Water, orthophosphoric acid (AR grade), Acetonitrile (HPLC grade), Methanol (HPLC grade) was used to develop the method.

\section{Instrumentation}

Shimadzu HPLC model LC $2010 \mathrm{C}_{\text {нт }}$ system equipped with binary gradient capability, UV detector, an auto sampler and column oven connected to a data acquisition system and processing system LabSolution version 5.2 was used to perform development and validation. A stainless-steel column filled with porous silica particles chemically bonded with Octadecyl silane \{YMC Triart C18 (250 x 4.6) mm, $5 \mu \mathrm{m}$, made: Japan $\}$ was used to achieve the determination of the content of imp-1, imp- 2 and imp-3 in $\alpha$-kvc. An analytical weight balance (made by Shimadzu, Japan) was used for weighing purposes.

\section{Preparation of Mobile phase A}

Accurately $1.0 \mathrm{~mL}$ of ortho-Phosphoric acid was pipetted and transferred into a $1000 \mathrm{~mL}$ measuring cylinder and diluted to $1000 \mathrm{~mL}$ with distilled water, mixed thoroughly, filtered through $0.45 \mu$ filter and sonicated to degas it.

\section{Preparation of Mobile phase B}

Acetonitrile and Methanol in the ratio of 9:1 were mixed and sonicated to degas it.

\section{Chromatographic Condition}

YMC Triart C18 ( $250 \times 4.6) \mathrm{mm}, 5 \mu \mathrm{m}$, made: Japan was used to analyze targeted molecules at column oven temperature $35^{\circ} \mathrm{C}$ and the flow rate was maintained $1.0 \mathrm{~mL} / \mathrm{min}$. The sample injection volume was 
$20 \mu 1$ and the sample temperature was kept at $25^{\circ} \mathrm{C}$. The UV detector was set to a wavelength of $210 \mathrm{~nm}$ to monitor the presence of targeted molecules. The chromatographic Gradient System Runtime was 40 minutes. A degassed mixture of Water: Acetonitrile in the ratio of 1:1 was used for rinse purpose.

\section{Method Development}

The analytical method developed here has consisted of mobile phase selection, detection wavelength selection and stationary phase selection. For this purpose, a literature survey has been optimized. The physical and chemical properties of chemicals and reagents used here have been studied.

\section{Mobile Phase Selection}

After some trial and error better chromatographic compatibility, resolution and selectivity have been achieved by using an aqueous orthophosphoric acid solution prepared as above as mobile phase- $\mathrm{A}$ and the mixture of Acetonitrile and Methanol in the ratio of 9:1 as mobile phase-B in the gradient form given in Table-1.

\section{Column Selection}

Among the column chemistry available in the lab a stainless-steel column filled with porous silica particles chemically bonded with Octadecyl silane C18 having specifications ( $250 \times 4.6 \mathrm{~mm}, 5 \mu \mathrm{m})$ was found to generate better results.

\begin{tabular}{c|c|c}
\multicolumn{3}{|c}{ Table-1: Gradient Composition } \\
\hline Time in Minutes & Mobile Phase A (\%v/v) & Mobile Phase B (\%v/v) \\
\hline Initial & 98 & 2 \\
\hline 5 & 98 & 2 \\
\hline 25 & 50 & 50 \\
\hline 27 & 98 & 2 \\
\hline 40 & 98 & 2 \\
\hline
\end{tabular}

\section{Detection Wavelength Selection}

On the base of the method studied given in reference ${ }^{11}$ for the first wavelength of $215 \mathrm{~nm}$ was used to detect the targeted molecules. But maximum chromatographic compatibility was observed with the wavelength of $210 \mathrm{~nm}$, so it has been selected to optimize the targeted molecules in the proposed method.

\section{Preparation of Diluent}

A mixture of Water and Acetonitrile in 9:1 ratio was prepared and sonicated to degas it for 5 minutes.

\section{Preparation of Standard Dilution Solution of $\alpha$-kve}

A solution of $\alpha-k v c$ having was prepared by accurately weighed $50.050 \mathrm{mg}$ of working standard of $\alpha-\mathrm{kvc}$ and transferred into a $50 \mathrm{~mL}$ volumetric flask, added about $35 \mathrm{~mL}$ of diluent into it and sonicated with occasional swirling to dissolve the solid. Diluted to the volume with diluent and mixed thoroughly. This solution was used for dilution purposes also.

\section{Preparation of Sample Solution}

The sample solution of $\alpha$-kvc was prepared by accurately weighed $40.05 \mathrm{mg}$ of $\alpha$-kvc (samples, different batch) and was transferred into a $10 \mathrm{~mL}$ volumetric flask. Added about $8 \mathrm{~mL}$ of diluent into it. Sonicated with occasional swirling to dissolve the solid. Diluted to the volume with diluent and mixed thoroughly.

\section{A stock solution of Imp- 1, 2 and 3}

Accurately weighed and transferred $10.010 \mathrm{mg}$ of Imp-1, $10.030 \mathrm{mg}$ of Imp-2 and $10.080 \mathrm{mg}$ of Imp-3 into a $10 \mathrm{~mL}$ volumetric flask separately and added $7 \mathrm{~mL}$ of diluent in each flask, sonicated to dissolve and made the volume with further adding diluent into each volumetric flask.

\section{Peak Identification Solution}

Accurately pipetted $1 \mathrm{~mL}$ of each of stock solution of Imp- 1, 2 and 3 into a $10 \mathrm{~mL}$ volumetric flask and added $10 \mathrm{mg}$ accurately weighed of standard $\alpha$-kvc and added $5 \mathrm{~mL}$ of the diluent, sonicated for 5 minutes and made the volume up to the mark with the diluent. 
RASĀYAN J. Chem.

Vol. 14 | No. 2 |950-958| April - June | 2021

\section{RESULTS AND DISCUSSION}

Concerning the method development, the chromatographic parameters given in the Table- 2 were found suitable for the validation given here.

Table-2: Chromatographic Conditions

\begin{tabular}{c|c}
\hline Parameters & Optimum Condition \\
\hline Mobile Phase-A & $0.1 \%$ orthophosphoric acid in water \\
\hline Mobile Phase-B & Acetonitrile: Methanol $(90: 10)$ \\
\hline Column & YMC Triart C18(250 x $4.6 \mathrm{~mm}, 5 \mu \mathrm{m}$ particle size $)$ \\
\hline Flow Rate & $1.0 \mathrm{~mL} / \mathrm{min}$ \\
\hline Gradient Elution at & As per table 1 \\
\hline Detection Wavelength & $210 \mathrm{~nm}$ \\
\hline Diluent & Water: Acetonitrile $(90: 10)$ \\
\hline Injection Volume & $20 \mu \mathrm{L}$ \\
\hline
\end{tabular}

\section{Method Validation}

The method for the determination and quantification of the $\alpha-k v c$ and related known impurities in bulk drug was further validated as ICH Q2 (R1) guidelines. ${ }^{12}$

\section{Specificity}

The Specificity of the method was evaluated by $1.0 \mathrm{~mL}$ from each stock solution- 1,2 and 3 were pipetted and transferred into $10 \mathrm{~mL}$ of volumetric flask individually and diluted up to mark and these solutions were injected into the system (Fig.-2 to 4). The sample solution $\alpha$-kvc prepared as above was also injected to examine. (See Fig.-5). The chromatogram of the sample solution showed the peaks of some unknown impurities present in the sample of $\alpha$-kvc. A solution having the concentration at the $100 \%$ level of specification of impurities spiked studied here was injected with the sample preparation to examine for if any interference could be observed with Imp-1, Imp-2 and Imp-3 peaks (see Fig.-6). The Specificity of the method was further evaluated by injecting the blank solution and observing that any interference with the peaks of interest in the chromatograms obtained from the Standard Solution. To identify the retention time of each component the peak identification solution prepared as above was injected (see Fig.-7). The retention time for $\alpha$-kvc was observed at 14.85 minutes. Peak shapes were found satisfactory for each known impurity. It has been confirmed that no interference was observed in the elution zone of the blank/diluent. Specificity data also revealed that the impurities do not elute in the elution zone of the $\alpha$-kvc retention time. The results of specificity Data for individual Impurity and spiked Sample summarized in Table- 3 and 4 respectively.

Table-3: Specificity Results

\begin{tabular}{c|c}
\hline Compound Name & Retention Time (minutes) \\
\hline Imp-1 & 3.80 \\
\hline$\alpha$-kvc & 14.74 \\
\hline Imp-2 & 16.58 \\
\hline Imp-3 & 19.30 \\
\hline Blank & - \\
\hline
\end{tabular}

Table-4: Specificity Results, Spiked Sample Individual Impurities

\begin{tabular}{c|c|c}
\hline $\begin{array}{c}\text { Compound } \\
\text { Name }\end{array}$ & $\begin{array}{c}\text { Retention Time } \\
\text { (minutes) }\end{array}$ & $\begin{array}{c}\text { Relative } \\
\text { Retention } \\
\text { Time(about) }\end{array}$ \\
\hline Imp-1 & 3.81 & 0.26 \\
\hline$\alpha-\mathrm{kvc}$ & 14.74 & 1.00 \\
\hline Imp-2 & 16.59 & 1.13 \\
\hline Imp-3 & 19.31 & 1.31 \\
\hline
\end{tabular}


RASĀYAN J. Chem.

Vol. 14 | No. 2 |950-958| April - June | 2021

mAU

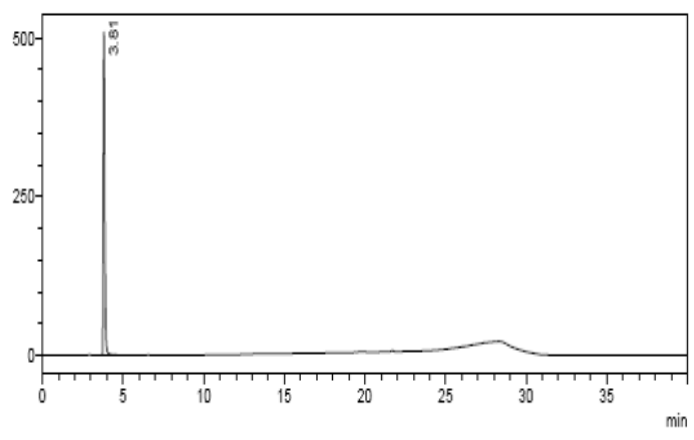

Fig.-2: Chromatogram of Individual Imp-1 (Specificity)

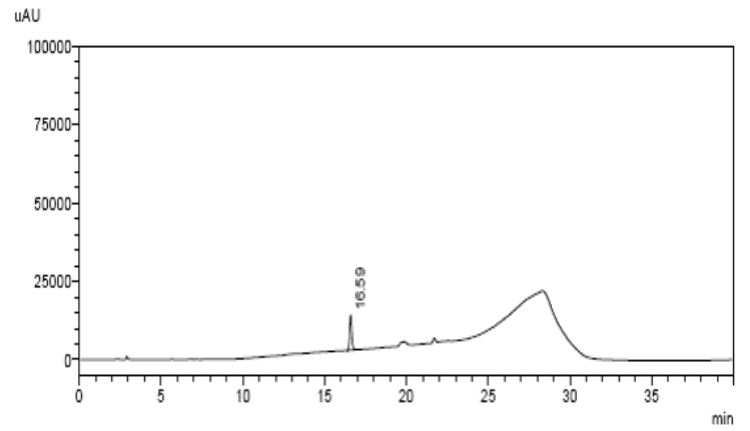

Fig.-4: Chromatogram of Individual Imp-3
mAU

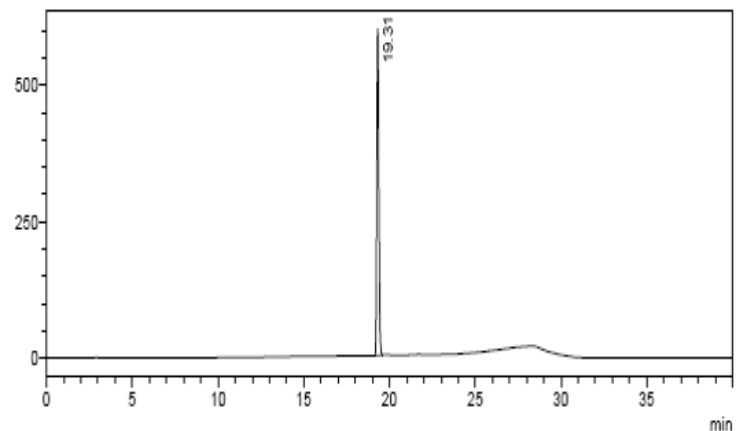

Fig.-3: Chromatogram of Individual Imp-2 (Specificity) (5-(Propan-2-Ylidene) imidazolidine-2,4 dione)

UAU

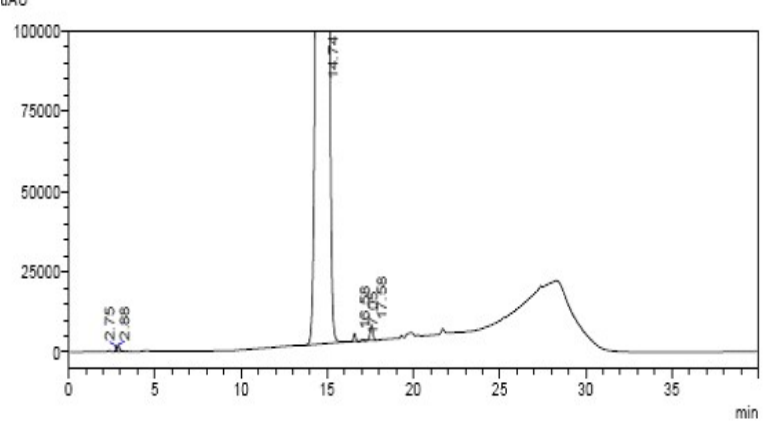

Fig.-5: Chromatogram of $\alpha-k v c$ as such (Specificity)(DL-2-Hydroxy-3-Methylbutyric acid)

\section{System Suitability}

For the study of system suitability, a solution having a concentration of $20 \mu \mathrm{g} / \mathrm{mL}$ (specification level) of each component studied here was prepared. For these purposes, different solutions were made as described below:

i. $\quad 2 \mathrm{~mL}$ solution was pipetted from the standard dilution solution into $10 \mathrm{ml}$ volumetric flask and made the volume up to mark with the diluent.

ii. $\quad 2 \mathrm{~mL}$ of each solution of the stock solution of Imp-1,2 and 3 were pipetted and transferred into a $10 \mathrm{~mL}$ volumetric flask and made the volume with the diluent

iii. Further took $1 \mathrm{~mL}$ of each the solution prepared as above into a $10 \mathrm{~mL}$ volumetric flask and made the volume to the mark with the diluent. This solution was used to evaluate the system suitability of the method developed by injecting the replicate injections at the specification level. The chromatogram obtained here was represented by Fig.-8.

The theoretical plates are obtained greater than 2000 by the method developed for all substances studied here. Moreover, the chromatogram of the peak identification solution indicates the system suitability of the test. The system suitability data were obtained according to Table-5. The Relative Standard Deviation (\%RSD) found $0.0,0.3,0.7$ and 0.0 for Imp-1, $\alpha-\mathrm{kvc}$, Imp-2 and Imp-3 respectively.

Table-5: System Suitability Data

\begin{tabular}{c|c|c|c|c}
\hline Description & Imp-1 & $\alpha$-kvc & Imp-3 & Imp-2 \\
\hline Conc. Of Solution $(\mu \mathrm{g} / \mathrm{ml})$ & 20.00 & 20.00 & 20.00 & 20.00 \\
\hline $\begin{array}{c}\text { Conc. With respect to Test } \\
\text { in Percentage (\%) }\end{array}$ & 0.50 & 0.50 & 0.50 & 0.50 \\
\hline Average (n=6) & 633221 & 162154 & 19320 & 927079 \\
\hline Standard Deviation & 107 & 549 & 127 & 204 \\
\hline \%RSD & 0.02 & 0.34 & 0.66 & 0.02 \\
\hline
\end{tabular}




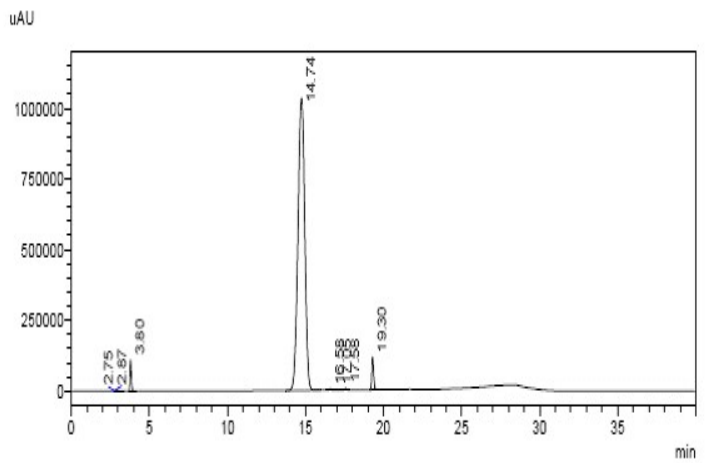

Fig.-6: Chromatogram of Spiked Solution at 100\% level of specification (Specificity)
MAU

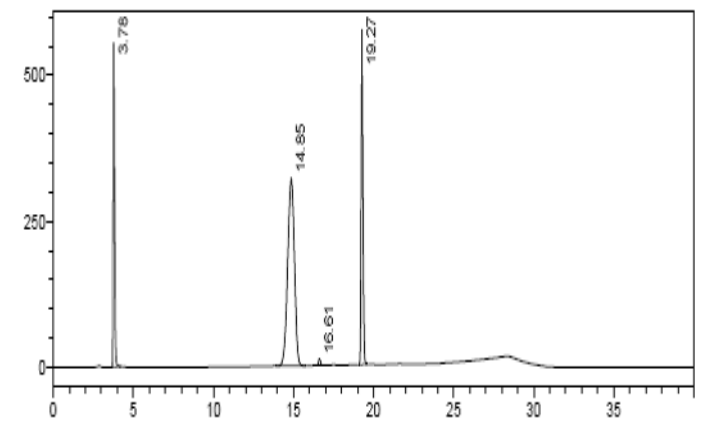

Fig.-7: chromatogram of peak identification solution

\section{LOD and LOQ}

Limit of Detection (LOD) and Limit of Quantification (LOQ) were derived based on signal to noise ratio. Each component was injected at the concentration level giving a minimum detectable peak. Here minimum detectable peak area war observed for the concentration of $0.15 \mu \mathrm{g} / \mathrm{mL}$ for Imp- $1,0.3 \mu \mathrm{g} / \mathrm{mL}$ for $\alpha-\mathrm{kvc}$, $0.15 \mu \mathrm{g} / \mathrm{mL}$ for Imp-2 and $0.3 \mu \mathrm{g} / \mathrm{mL}$ for Imp-3.

Here the LOD and LOQ value derived using the equations below,

$\mathrm{LOD}=3 \mathrm{X}$ The concentration at minimum detectable peak observed for the solution $\mathrm{LOQ}=3 \times \mathrm{LOD}$

The LOD values derived here are $0.45 \mu \mathrm{g} / \mathrm{mL}, 0.9 \mu \mathrm{g} / \mathrm{mL}, 0.45 \mu \mathrm{g} / \mathrm{mL}$ and $0.9 \mu \mathrm{g} / \mathrm{mL}$ for Imp- $1, \alpha-\mathrm{kvc}$, Imp-2 and Imp-3 respectively.

The LOQ values derived here are $1.35 \mu \mathrm{g} / \mathrm{mL}, 2.7 \mu \mathrm{g} / \mathrm{mL}, 1.35 \mu \mathrm{g} / \mathrm{mL}$ and $2.7 \mu \mathrm{g} / \mathrm{mL}$ for Imp-1, $\alpha-\mathrm{kvc}$, Imp-2 and Imp-3 respectively.

\section{Linearity Study}

Linearity of the detector response for the working standard of $\alpha-\mathrm{kvc}$ and the imp-1, imp-2 and imp-3 were determined across the range of $5 \%$ to $120 \%$ of the specification limit.

The proper concentration needed here had been prepared from stock solution of Imp-1, 2 and 3 by pipetting $2 \mathrm{~mL}$ of each solution and transferred into $10 \mathrm{~mL}$ volumetric flask separately and made the volume up to mark for each flask. These solutions were used for the dilution purpose for the Imp-1, 2 and 3 described in the Table-6. For the linearity study of $\alpha-k v c$ standard dilution, solution had been used for dilution purpose. $2 \mathrm{~mL}$ solution was pipetted and transferred into a $10 \mathrm{~mL}$ volumetric flask and diluted with the diluent up to the mark. This solution was used to get the proper concentration required for the study of linearity of $\alpha$ kvc which was shown by the Table-6.

On the base of the linearity study, the linearity graph was obtained for each component study here. Different components of the regression equation were obtained as given in Table- 6 . The predicted value LOD of $\alpha$ kvc, imp-1, imp-2 and imp-3 were found $0.54 \mu \mathrm{g} / \mathrm{mL}, 0.21 \mu \mathrm{g} / \mathrm{mL}, 0.24 \mu \mathrm{g} / \mathrm{mL}$ and $0.31 \mu \mathrm{g} / \mathrm{mL}$ respectively. The predicted LOQ value of $\alpha-\mathrm{kvc}$, imp-1, imp-2 and imp-3 were found $1.65 \mu \mathrm{g} / \mathrm{mL}, 0.64$ $\mu \mathrm{g} / \mathrm{mL}, 0.72 \mu \mathrm{g} / \mathrm{mL}$ and $0.94 \mu \mathrm{g} / \mathrm{mL}$ respectively. The predicted value of LOQ and LOD value was calculated using the equations given below:

$$
\begin{aligned}
& \text { LOQ }=\frac{10 \times \text { Residual Standard Deviation }}{\text { Slope }} \\
& \text { LOD }=\frac{3.3 \times \text { Residual Standard Deviation }}{\text { Slope }}
\end{aligned}
$$

The results found in the linearity study were summarized in Table-6. 
RASĀYAN J. Chem.

Vol. 14 | No. 2 |950-958| April - June | 2021

Table-6: Linearity Study

\begin{tabular}{|c|c|c|c|c|c|c|c|c|c|c|c|}
\hline \multirow{2}{*}{$\begin{array}{c}\text { S. } \\
\text { No. }\end{array}$} & \multirow[b]{2}{*}{$\begin{array}{l}\% \text { level } \\
\text { of } \\
\text { linearity } \\
\text { conc. }\end{array}$} & \multirow[b]{2}{*}{$\begin{array}{l}\text { Pipetted } \\
\text { volume } \\
(\mathrm{mL})\end{array}$} & \multirow[b]{2}{*}{$\begin{array}{l}\text { Made } \\
\text { up of } \\
\text { vol. } \\
(\mathrm{mL})\end{array}$} & \multicolumn{2}{|l|}{ Imp-1 } & \multicolumn{2}{|l|}{$\alpha-\mathrm{kvc}$} & \multicolumn{2}{|l|}{ Imp-2 } & \multicolumn{2}{|l|}{ Imp-3 } \\
\hline & & & & $\begin{array}{c}\text { Conc. } \\
(\mu \mathrm{g} / \mathrm{mL})\end{array}$ & Area & $\begin{array}{c}\text { Conc. } \\
(\mu \mathrm{g} / \mathrm{mL})\end{array}$ & Area & $\begin{array}{c}\text { Conc. } \\
(\mu \mathrm{g} / \mathrm{mL})\end{array}$ & Area & $\begin{array}{c}\text { Conc. } \\
(\mu \mathrm{g} / \mathrm{mL})\end{array}$ & Area \\
\hline 1 & 120 & 1.20 & 10 & 24.00 & 763964 & 24.00 & 197536 & 24.00 & 1116787 & 24.00 & 23427 \\
\hline 2 & 100 & 1.00 & 10 & 20.00 & 633017 & 20.00 & 161666 & 20.00 & 926560 & 20.00 & 19290 \\
\hline 3 & 80 & 0.80 & 10 & 16.00 & 507445 & 16.00 & 129315 & 16.00 & 739528 & 16.00 & 15510 \\
\hline 4 & 30 & 0.30 & 10 & 6.01 & 188208 & 6.01 & 46983 & 6.02 & 271144 & 6.05 & 5897 \\
\hline 5 & 10 & 0.10 & 10 & 2.00 & 64206 & 2.00 & 15856 & 2.01 & 90746 & 2.02 & 1961 \\
\hline 6 & 5 & 0.50 & 100 & 1.00 & 32893 & 1.00 & 7519 & 1.00 & 44823 & 1.01 & 981 \\
\hline \multicolumn{4}{|c|}{ Slope } & \multicolumn{2}{|c|}{31751.7} & \multicolumn{2}{|c|}{8212.2} & \multicolumn{2}{|c|}{46608.8} & \multicolumn{2}{|c|}{971.4} \\
\hline \multicolumn{4}{|c|}{ Intercept } & \multicolumn{2}{|c|}{-242.02} & \multicolumn{2}{|c|}{-1307.7} & \multicolumn{2}{|c|}{-4636.5} & \multicolumn{2}{|c|}{-6.4} \\
\hline \multicolumn{4}{|c|}{ Coefficient of determination $\left(\mathrm{r}^{2}\right)$} & \multicolumn{2}{|c|}{1.0000} & \multicolumn{2}{|c|}{0.9998} & \multicolumn{2}{|c|}{1.0000} & \multicolumn{2}{|c|}{0.9999} \\
\hline \multicolumn{4}{|c|}{ STEYX } & \multicolumn{2}{|c|}{2025.7} & \multicolumn{2}{|c|}{1354.0} & \multicolumn{2}{|c|}{3370.8} & \multicolumn{2}{|c|}{91.0} \\
\hline \multicolumn{4}{|c|}{$\mathrm{LOQ}(\mu \mathrm{g} / \mathrm{mL})$} & \multicolumn{2}{|c|}{0.64} & \multicolumn{2}{|c|}{1.65} & \multicolumn{2}{|c|}{0.72} & \multicolumn{2}{|c|}{0.94} \\
\hline \multicolumn{4}{|c|}{$\mathrm{LOD}(\mu \mathrm{g} / \mathrm{mL})$} & \multicolumn{2}{|c|}{0.21} & \multicolumn{2}{|c|}{0.54} & & & 0.3 & \\
\hline
\end{tabular}

STEYX $=$ Residual Standard Deviation

\section{Study of Precision at LOD and LOQ Concentration Level}

This work has been tested the precision of the validation process for the solution prepared of known concentrations.

The precision of $\alpha-\mathrm{kvc}$ related impurities at about Limit of detection and Limit of quantification was conducted. Six test preparations at LOD concentration level and six test preparations at LOQ concentration level for each impurity along with $\alpha$-kvc were made and injected into the system.

The Relative Standard Deviation (RSD) values observed at LOQ level of concentration were $0.4 \%, 3.8 \%$, $0.3 \%$ and $1.7 \%$ for the Imp- $1, \alpha-\mathrm{kvc}$, Imp-2 and Imp-3 respectively. The Relative Standard Deviation (RSD) values observed at LOD concentration level were $0.4 \%, 3.1 \%, 0.7 \%$ and 5.5 for the Imp-1, $\alpha$-kvc, Imp-2 and Imp-3 respectively. These data are summarized in Table- 7 and 8 and graphical representation is given by Fig.-9 and 10.

Table-7: Precision Study at LOQ Concentration Level

\begin{tabular}{c|c|c|c|c}
\hline Description & Imp-1 & $\alpha$-kvc & Imp-2 & Imp-3 \\
\hline $\begin{array}{c}\text { Conc. of Solution } \\
(\mu \mathrm{g} / \mathrm{mL})\end{array}$ & 1.00 & 2.00 & 1.00 & 2.00 \\
\hline $\begin{array}{c}\text { Conc. of Solution in Percentage } \\
(\%) \text { with respect test }\end{array}$ & 0.025 & 0.05 & 0.025 & 0.05 \\
\hline $\begin{array}{c}\text { Average area } \\
(\mathrm{n}=6)\end{array}$ & 32893 & 15298 & 44823 & 1961 \\
\hline Standard Deviation & 139 & 580 & 145 & 33 \\
\hline \%RSD & 0.4 & 3.8 & 0.3 & 1.7 \\
\hline
\end{tabular}

Table-8: Precision Study at LOD Concentration Level

\begin{tabular}{c|c|c|c|c}
\hline Description & Imp-1 & $\alpha$-kvc & Imp-2 & Imp-3 \\
\hline $\begin{array}{c}\text { Conc. of Solution } \\
(\mu \mathrm{g} / \mathrm{mL})\end{array}$ & 0.50 & 1.00 & 0.50 & 1.00 \\
\hline $\begin{array}{c}\text { Conc. of Solution in Percentage } \\
(\%) \text { with respect to test }\end{array}$ & 0.013 & 0.025 & 0.013 & 0.025 \\
\hline $\begin{array}{c}\text { Average area } \\
(\mathrm{n}=6)\end{array}$ & 16336 & 7088 & 22031 & 942 \\
\hline Standard Deviation & 68 & 218 & 162 & 52 \\
\hline \%RSD & 0.4 & 3.1 & 0.7 & 5.5 \\
\hline
\end{tabular}


RASĀYAN J. Chem.

Vol. 14 | No. 2 |950-958| April - June | 2021

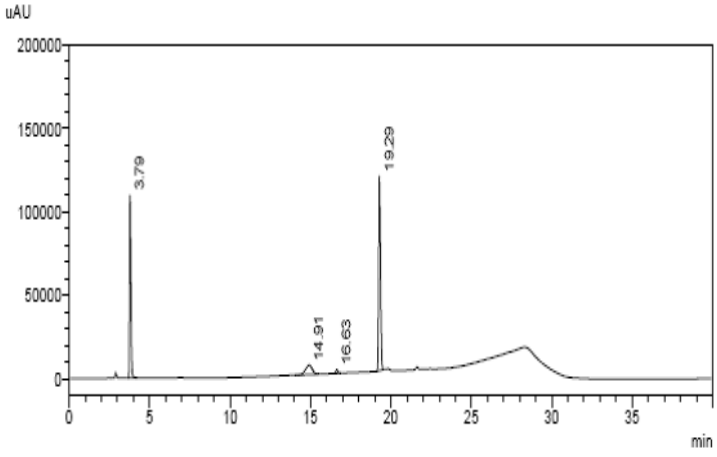

Fig.-8: Chromatogram of System Suitability at Specification Level Solution

UAU

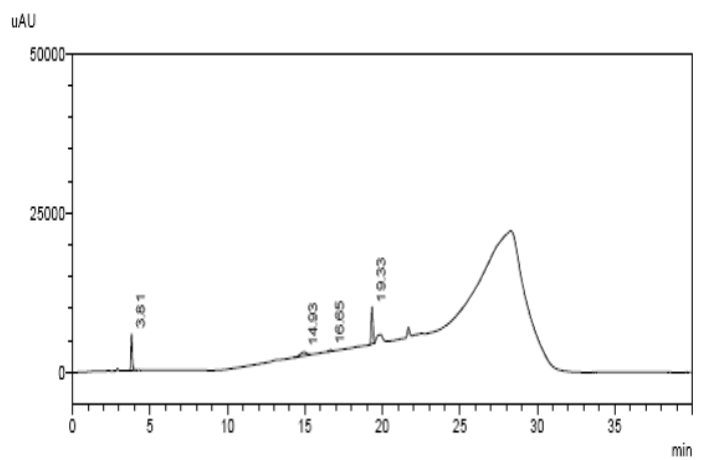

Fig.-9: Chromatogram of LOQ Level Concentration Solution

\section{The Relative Response Factor}

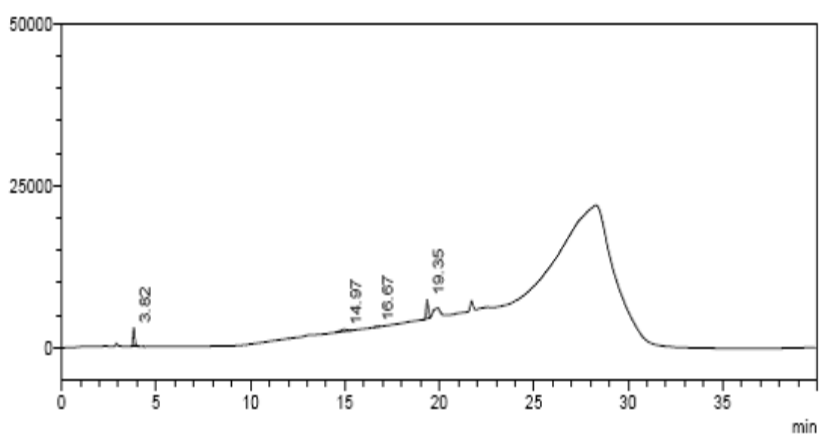

Fig.-10: Chromatogram of LOD Level Concentration Solution

The Relative Response Factor (RRF) of each known impurity and Alpha Keto Valine Calcium was calculated using the slope value obtained from the linearity data mentioned above. The Relative Response Factor (RRF) of each known impurity was calculated by using the following formula:

$\mathrm{RRF}=$ The slope of $\alpha-\mathrm{kvc}(\mathrm{A}) /$ The slope of each individual known impurity linearity curve (B)

The RRF value founded was 0.26 for Imp-1, 0.18 for Imp-2 and 8.45 for Imp-3.

\section{Accuracy (Recovery)}

A study of recovery of $\alpha$-kvc related to known impurities in a spiked sample of $\alpha$-kvc test preparation was conducted. Samples were prepared by spiking of all known impurities in test preparation at LOQ level, $80 \%, 100 \%$ and $120 \%$ of the specification level concentration.

When a control sample of $\alpha$-kvc was injected at test concentration, with some peaks of unknown impurities, a peak of Imp-3 was also observed (see Fig.-5). The amount of Imp-3 presented in the sample was 0.54 concerning test. \%recoveries of $\alpha-k v c$ related known impurities were calculated by established RRF as described in Table- 9 .

\begin{tabular}{|c|c|c|c|c|}
\hline Level & Amount Present & Amount Added & Amount Found & \%Recovery \\
\hline \multicolumn{5}{|c|}{$\begin{array}{c}\text { Hydantoin } \\
\text { (Conc. with respect to test in percentage }(\%))\end{array}$} \\
\hline $120 \%$ & \multirow{4}{*}{00} & 0.60 & 0.61 & 101.7 \\
\hline $100 \%$ & & 0.50 & 0.51 & 102.0 \\
\hline $80 \%$ & & 0.40 & 0.41 & 102.5 \\
\hline LOQ Level & & 0.025 & 0.026 & 104.0 \\
\hline
\end{tabular}

DL-2-Hydroxy-3-Methylbutyric acid

(Conc. with respect to test in percentage (\%)) 
RASĀYAN J. Chem.

Vol. 14 | No. 2 |950-958| April - June | 2021

\begin{tabular}{|c|c|c|c|c|}
\hline $120 \%$ & \multirow{4}{*}{0.54} & 0.60 & 1.2 & 108.3 \\
\hline $100 \%$ & & 0.50 & 0.99 & 102.0 \\
\hline $80 \%$ & & 0.40 & 0.88 & 97.5 \\
\hline LOQ Level & & 0.050 & 0.56 & 100.0 \\
\hline \multicolumn{5}{|c|}{$\begin{array}{l}\text { 5-(Propan-2-Ylidene) imidazolidine-2,4-dione } \\
\text { (Conc. with respect to test in percentage }(\%) \text { ) }\end{array}$} \\
\hline $120 \%$ & \multirow{4}{*}{00} & 0.60 & 0.61 & 103.3 \\
\hline $100 \%$ & & 0.50 & 0.50 & 104.0 \\
\hline $80 \%$ & & 0.40 & 0.40 & 102.5 \\
\hline LOQ Level & & 0.025 & 0.030 & 116.0 \\
\hline
\end{tabular}

\section{CONCLUSION}

This method validated for the $\alpha-\mathrm{kvc}$ and related known impurities by using the column described as above as per the ICH guidelines. This method can be adopted in bulk and formulation industries for $\alpha$-kvc and its impurities. Good results were observed by this method and the validation parameters likewise linearity, specificity, method precision and assay accuracy had been generated. By this method, this work concluded that the results obtained through the column are accurate and precise and the method can quantify and detect known all impurities summarized here with a good precise level. Hence this method can be used for the determination of $\alpha-\mathrm{kvc}$ and its impurities for formulation purposes. The specificity data given here showed the ability of the method to correctly identify and quantify the analyte in the presence of all potential sample components.

\section{ACKNOWLEDGEMENT}

This research was not possible without the help of Hardik Vyas, so special thanks to providing the standards required.

\section{REFERENCES}

1. M. Walser, A. W. Coulter, S. Dighe, and F. R. Crantz, The Journal of Clinical Investigation, 52, 678(1973), DOI:10.1172/JCI107229

2. J. Burns, E. Cresswell, S. Ell, M. Fynn, M. A. Jackson, H. A. Lee, P. Richards, A. Rowlands, S. Talbot, American Journal of Clinical Nutrition, 31,1767(1978), DOI:10.1093/ajen/31.10.1767

3. P. A. Anderson, K. L. Cippolo, T. G. Mohacsi, United States, Patent Number: 4, 957, 938. Date of Patent: Sep. 18, 1990, Available from http://patentimages.storage.googleapis.com

4. E. Riedel, H. Hampl, M. Nundel, G. Farshidfar, Nephrology Dialysis Transplantation, 7,117(1992), DOI: 10.1093/oxfordjournals.ndt.a092079

5. M. Sevgi, O. Nese, A. Aysegul, Pediatric Nephrology, 20, 950(2005), DOI:10.1007/s00467-005-18606

6. M. Nakajima, H. Yamanaka, R. Fujiwara, M. Katoh, T. Yokoi, Drug Metabolism and Disposition, 35,1679(2007),DOI:10.1124/dmd.107.015909

7. C.F. Thorn, M. Whirl-Carrillo, J.S. Leeder, T.E. Klein, R.B. Altman, Pharmacogenetic Genomics, 22,466(2012), DOI:10.1097/fpc.0b013e32834aeedb

8. T. Bergstrom, J. Greter, A. Levin, G. Steen, N. Tryding and U. Wass, Scandinavian Journal of Clinical and Laboratory Investigation, 41,117(1981), DOI:10.3109/00365518109092023

9. http://drugs.ncats.io, record details no. 02X1W97FWN

10. R. Kandar, P. Zakova, J. Jirosova, M. Sladka, Clinical Chemistry and Laboratory Medicine, 47, 565(2009),DOI:10.1515/CCLM.2009.123

11. M. Walser, L. M. Swain, V. Alexander, Analytical Biochemistry, 164, 287(1987), DOI:10.1016/00032697(87)90494-5

12. G. A. Qureshi, Journal of Chromatography, 400, 91(1987), DOI:10.1016/S0021-9673(01)81602-2

13. R. Thakkar, H. Saravaia, M. Ambasana, A. Shah, Journal of Liquid Chromatography \& Related Technologies, 35,2125(2012), DOI:10.1080/10826076.2011.629385

14. ICH Guideline Q2 (R1), Validation of Analytical Procedure: Text and Methodology, November 2005

[RJC-6272/2020] 